\title{
ANALISIS STATISTIKA PENGARUH CURAH HUJAN TERHADAP BANJIR DI JAKARTA MELALUI PEMODELAN MATEMATIKA
}

\author{
Stephanie $^{I^{*}}$, Owen Nixon Jimawan ${ }^{2}$, Devina Jayadi ${ }^{1}$ \\ ${ }^{I}$ Mathematics, Bandung Institute of Technology, Bandung, Indonesia \\ ${ }^{2}$ Geological Engineering, Bandung Institute of Technology, Bandung, Indonesia \\ "Email: stephaniefani0803@gmail.com
}

\begin{abstract}
ABSTRAK
Kota pesisir di Asia, termasuk Jakarta, sedang berusaha melawan dampak dari perubahan iklim, seperti banjir, kenaikan muka air laut, badai, dan lain sebagainya yang mampu mempengaruhi kehidupan manusia dan infrastruktur. Bencana banjir merupakan bencana dengan frekuensi terbesar dari sekian banyak bencana yang dihasilkan oleh perubahan iklim tersebut. Timbulnya bencana hidrometeorologi ini tentunya disebabkan oleh curah hujan dan berbagai faktor pemicu lainnya. Curah hujan merupakan fenomena alam yang menjadi komponen utama siklus air. Perhatian terhadap perubahan iklim telah memperkuat kebutuhan akan informasi akurat mengenai variasi statistik dari karakteristik curah hujan. Uji statistik mengonfirmasi bahwa suatu model yang diusulkan dapat digunakan untuk memprediksi jumlah curah hujan di suatu wilayah. Makalah ini mengindentifikasi perubahan dari model curah hujan dahulu dan saat ini melalui kronologi curah hujan untuk mengestimasi jumlah curah hujan pada tahun-tahun berikutnya dengan menggunakan model stokastik di Jakarta, Indonesia. Data diperoleh dari sejumlah stasiun pengamat cuaca di area studi untuk rentang periode 10 tahun sejak tahun 2007 hingga 2017. Analisis juga dilakukan untuk menjelaskan penggunaan pemodelan rantai Markov orde pertama untuk pengukuran curah hujan. Keterbatasan model rantai Markov berbasis Gamma yang menunjukkan masih adanya ketidakpastian orde yang optimal untuk sejumlah model diatasi dengan mencoba pengembangan model deret waktu (time series) untuk meningkatkan pemodelan yang dilakukan sebelumnya. Data curah hujan yang telah dimodelkan akan dibandingkan dengan analisis meteorologi untuk menghubungkannya dengan bencana banjir. Analisis dan pemodelan ini dapat dimodifikasi dan diaplikasikan untuk memprediksi curah hujan di wilayah lain dengan topografi dan iklim yang serupa setelah dilakukan sejumlah uji statistik.
\end{abstract}

Kata kunci: Banjir, curah hujan, rantai Markov, time series

\begin{abstract}
Coastal cities in Asia, including Jakarta, are struggling to counter climate changes effects, such as floods, sea level rises, storms, and the others that are able to affect human life and infrastructure. Flood is a natural disaster with the greatest frequency compared to other disasters generated by climate changes. This hydrometeorological disaster is certainly caused by rainfall and other factors. Rainfall is a natural phenomenon that becomes the main component of the water cycle. Attention to climate changes has reinforced the need for more accurate information on statistical variations of rainfall characteristics. The statistical test confirms that a proposed model can be used to predict the amount of rainfall in a region. This paper identifies changes from the previous and current rainfall models through the rainfall chronology to predict the amount of rainfall in subsequent years using stochastic models in Jakarta, Indonesia. Data were obtained from a number of weather observation stations in the study area for the 10 year period ranging from 2007 to 2017. Analysis was also conducted to explain the use of first-order Markov chain modeling for rainfall measurement. The limitations of the Markov chain model still indicates uncertainties for some cases, so they can be overcome by trying to develop a time series model to improve the previous modeling. The data that has been modeled will be compared with meteorological analysis to observe the relation with flood disasters. This analysis and modeling can be modified and applied to predict rainfall in other regions with similar topography and climate after a number of statistical tests were executed.
\end{abstract}

Keywords: Floods, Markov chain, rainfall, time series

\section{PENDAhUluAN}


Daerah pesisir di berbagai belahan dunia sedang menghadapi dampak buruk dari perubahan iklim, termasuk banjir, kenaikan permukaan air laut, badai yang meningkat, dan gelombang badai. Perubahan iklim ini pada akhirnya dapat mengakibatkan hilangnya banyak kehidupan dan infrastruktur, serta kerusakan pada ekonomi regional ataupun nasional. Menurut Satterthwaite (2008), perubahan iklim berpotensi mengintensifkan risiko banjir di suatu kota dalam tiga cara, yaitu permukaan air laut yang lebih tinggi dan gelombang badai, curah hujan yang lebih tinggi dari umumnya, dan perubahan aliran sungai yang cenderung meningkat, misalnya karena glasial meleleh. Sebagai salah satu kota besar dengan kepadatan penduduk tertinggi, Jakarta menjadi kota yang turut serta dalam menghadapi perubahan iklim global. Kota ini rentan terhadap banjir, naiknya air laut dan bencana alam lainnya serta bencana buatan manusia seperti polusi dan ekstraksi air tanah yang berlebihan. Yusuf dan Fransisco (2009) mencantumkan bahwa Jakarta sebagai salah satu kota pesisir yang paling rentan terhadap perubahan iklim di Asia Tenggara. Jakarta yang menempati lahan seluas 662 kilometer persegi dan jumlah penduduk 9,6 juta pada tahun 2010 ditambah sekitar 2,5 juta penumpang harian dari daerah sekitarnya juga merupakan magnet bagi para imigran yang mencari kondisi kehidupan yang lebih baik, kebanyakan imigran miskin. Sebagian besar masyarakat miskin tinggal di daerah kumuh di beberapa wilayah di Jakarta, yang sangat rentan terhadap banjir. Perubahan penggunaan lahan secara langsung dipengaruhi oleh sebagian besar kegiatan ekonomi, sosial, dan lingkungan, yang mencerminkan perkembangan dan pertumbuhan perkotaan (Litman, 1995). Masyarakat miskin cenderung menjadi kelompok yang paling rentan terhadap dampak terkait perubahan iklim.

Hujan, sebagai salah satu penyebab banjir, merupakan komponen utama dari siklus air dan bertanggung jawab untuk mendepositokan sebagian besar air tawar di bumi melalui proses siklus hidrologi di lingkungan. Perhatian terhadap perubahan iklim telah memperkuat kebutuhan akan informasi yang akurat mengenai variasi statistik dari karakteristik curah hujan sebab tingkat curah hujan bervariasi dalam waktu ke waktu, yang dipengaruhi oleh situasi iklim daerah setempat. Dalam penelitian ini, pemodelan curah hujan akan diprediksi berdasarkan data curah hujan tahun 2007 hingga 2017 dengan menggunakan metode stokastik dan diharapkan dapat memberikan hasil yang dapat diandalkan. Model stokastik digunakan dalam mengindentifikasi perubahan dari model curah hujan dahulu hingga kini melalui kronologi curah hujan untuk mengestimasi jumlah curah hujan pada tahun-tahun berikutnya. Data curah hujan yang telah dimodelkan akan dibandingkan dengan analisis meteorologi untuk menghubungkannya dengan bencana banjir.

\section{METODOLOGI PENELITIAN}

Data curah hujan yang digunakan adalah data curah hujan rata-rata per bulan di Jakarta yang diperoleh dari BMKG, yaitu dari bulan Januari 2007 sampai bulan Desember 2017. Penggunaan data dibagi menjadi dua, untuk pembentukan model (Januari 2007 - Desember 2016) dan untuk validasi model (Januari 2017 Desember 2017). Penggunaan metode rantai Markov dianggap kurang sesuai untuk memodelkan masalah curah hujan rata-rata per bulan sebab metode ini menggunakan matriks peluang. Oleh karena nilai keluarannya berupa peluang, maka metode rantai Markov hanya dapat memprediksi hari hujan atau hari tidak hujan, dan belum dapat memprediksi nilai curah hujan.

Pada akhirnya metode yang digunakan untuk memodelkan curah hujan rata-rata per bulan berupa model deret waktu dengan metode BoxJenkins, yaitu (1) Membuat plot data deret waktu. (2) Menguji kestasioneran data dengan uji Augmented Dicky-Fuller. (3) Apabila data belum stasioner atau terdapat unsur musiman, maka dilakukan diferensiasi data kemudian diuji ulang. (4) Mengidentifikasi model deret waktu sesuai dengan plot grafik PACF dan ACF. (5) Memeriksa kelayakan model dengan $R$ - squared, MAPE, dan Ljung-Box, lalu menentukan model yang terbaik. (5) Memprediksi (forecasting) curah hujan di tahun 2017 dengan model persamaan deret waktu yang ada, lalu membandingkannya dengan data validasi.

Kemudian setelah analisis curah hujan akan dilakukan estimasi hubungan curah hujan dengan potensi banjir melalui analisis curah hujan melalui periode ulang (T) dengan metode Gumbel. Berdasarkan analisis frekuensi hujan 
dengan metode Gumbel akan disusun suatu hubungan antara curah hujan harian maksimum dengan periode ulangan dan diakhiri dengan penginterpretasian peluang banjir.

\section{ANALISIS DAN PEMBAHASAN}

\subsection{Plot Data Deret Waktu}

Misalkan realisasi deret waktu $\left\{Y_{t}, \mathrm{t}=1,2, . ., 120\right\}$ dengan $Y_{t}$ suatu deret waktu curah hujan ratarata per bulan dari Januari 2007 sampai Desember 2016 (120 bulan).

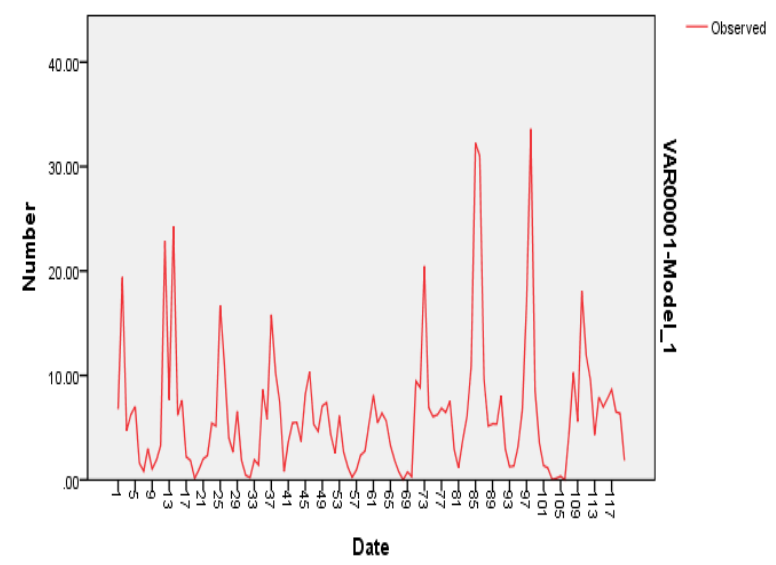

Gambar 1. Plot Data Deret Waktu

\subsection{Uji Kestasioneran Data (Augmented Dicky Fuller Test)}

Dilakukan untuk realisasi deret waktu $\left(Y_{t}\right)$, dengan hipotesis yang digunakan adalah:

$\mathrm{H}_{0}$ (hipotesis nol): Data tidak stasioner

$\mathrm{H}_{1}$ (hipotesis alternatif): Data stasioner

Berikut merupakan hasil dari Augmented Dicky Fuller Test:

Dickey-Fuller $=-6.0912$, Lag order $=4, \mathrm{p}$-value $=0.01$

Karena p-value $=0.01$, untuk taraf keberartian $\alpha=0.05, \mathrm{H}_{0}$ ditolak.

Maka, disimpulkan bahwa $Y_{t}$ stasioner.
3.2 Identifikasi model deret waktu sesuai plot $A C F$ dan PACF
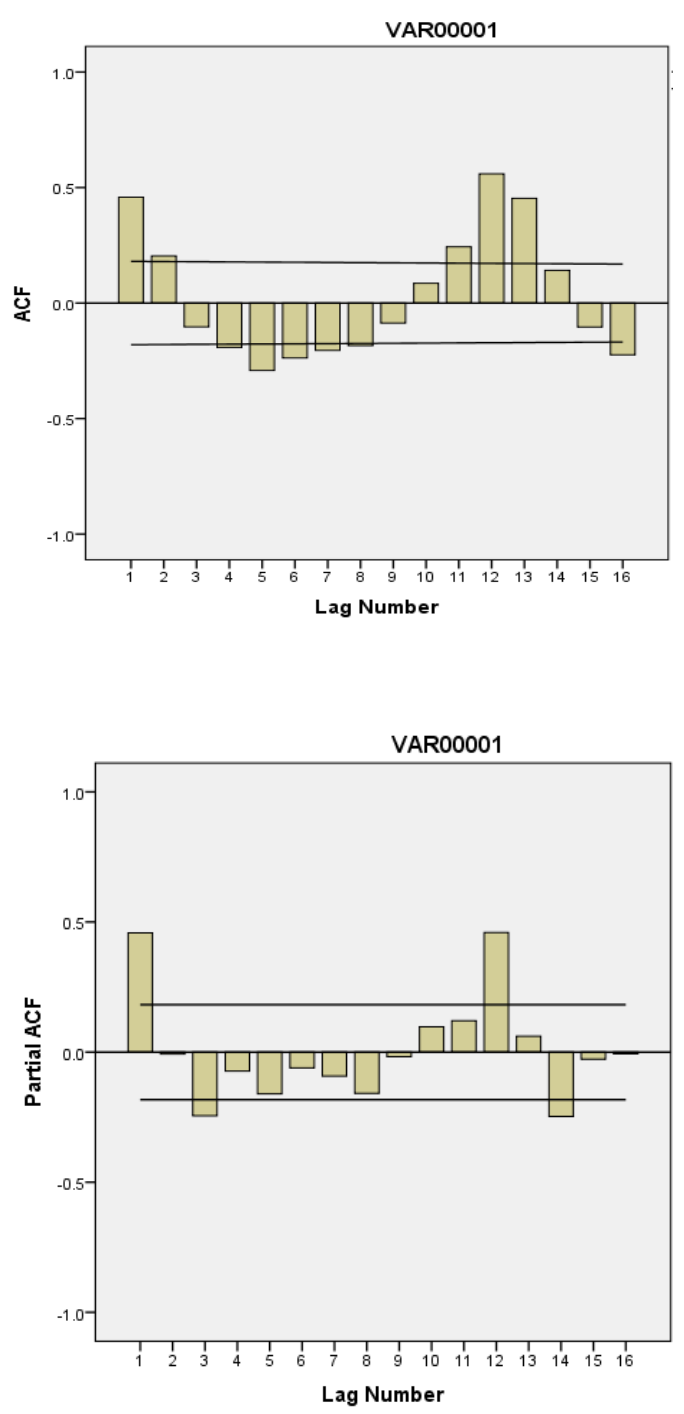

Gambar 2. Plot grafik ACF dan PACF dari $Y_{t}$

Dari grafik ACF dan PACF di atas, grafik ACF tidak terlihat terpotong (cut off) pada lag-lag awal (lag 1 sampai lag 10). Grafik ACF cenderung berbentuk sinusoidal atau biasanya disebut dying down. Grafik PACF terpotong (cut off) pada lag ke-1, tetapi dapat dilihat membesar pada lag ke-12 dan seterusnya. Oleh karena ACF dying down dan PACF cut off pada lag ke-1, maka dapat disimpulkan bahwa model deret waktu yang sesuai adalah model ARIMA dengan $\mathrm{AR}(1)$. 


\subsection{Penentuan Model ARIMA terbaik dengan $R$-squared dan MAPE}

Untuk menentukan model ARIMA yang terbaik dan paling sesuai, akan dibuat model dengan kombinasi dari orde $\mathrm{AR}=1$ dan $1 \leq \mathrm{MA} \leq 12$. Untuk masing-masing orde ARIMA, dihitung nilai Stationary $R$-squared dan MAPE (Mean Absolute Percentage Error).

Berikut ini adalah perbandingan dari orde-orde ARIMA yang dibentuk.

Tabel 1. Tabel Stationary $R$-squared dan MAPE dari masing-masing model ARIMA

\begin{tabular}{|c|c|c|}
\hline $\begin{array}{c}\text { Orde } \\
\text { ARIMA }\end{array}$ & $\begin{array}{c}\text { Stationary } \boldsymbol{R} \text { - } \\
\text { squared }\end{array}$ & MAPE \\
\hline $1,0,1$ & 0.211 & 240.728 \\
\hline $1,0,2$ & 0.235 & 223.284 \\
\hline $1,0,3$ & 0.203 & 227.891 \\
\hline $1,0,4$ & 0.254 & 231.793 \\
\hline $1,0,5$ & 0.293 & 269.874 \\
\hline $1,0,6$ & 0.364 & 224.833 \\
\hline $1,0,7$ & 0.380 & 225.652 \\
\hline $1,0,8$ & 0.380 & 219.811 \\
\hline $1,0,9$ & 0.352 & 233.742 \\
\hline $1,0,10$ & 0.438 & 217.895 \\
\hline $1,0,11$ & 0.416 & 198.338 \\
\hline $1,0,12$ & 0.498 & 220.058 \\
\hline
\end{tabular}

Dari tabel, dapat dilihat bahwa model ARIMA $(1,0,12)$ memiliki nilai Stationary $R$ squared yang paling besar dan nilai MAPE yang cukup kecil, walaupun bukan merupakan yang terkecil.

Maka dari itu, dapat disimpulkan bahwa model $\operatorname{ARIMA}(1,0,12)$ adalah model yang terbaik untuk $Y_{t}$.

\subsection{Uji Kecocokan Model dengan Uji Diagnosis Ljung-Box}

Untuk menguji kecocokan model $\operatorname{ARIMA}(1,0,12)$ dengan data yang ada, dilakukan Uji Diagnosis Ljung-Box dengan mengecek keberadaan korelasi sisaan antar lag.

Hipotesis yang digunakan dalam Uji Diagnosis Ljung-Box adalah:
$\mathrm{H}_{0}$ (hipotesis nol): Korelasi sisaan antar lag $=0$ $\mathrm{H}_{1}$ (hipotesis alternatif): Korelasi sisaan antar lag $\neq 0$

Berikut merupakan hasil dari Uji Diagnosis Ljung-Box:

$\mathrm{p}$-value $=0.053$

Untuk taraf keberartian $\alpha=0.05$, karena $\mathrm{p}$ value $>\alpha, \mathrm{H}_{0}$ tidak ditolak.

Maka, dapat disimpulkan bahwa tidak ada korelasi sisaan antar lag, sehingga model $\operatorname{ARIMA}(1,0,12)$ adalah model yang cocok dengan $Y_{t}$.

\subsection{Persamaan Model Deret Waktu}

Dengan menggunakan model ARIMA(1,0,12), persamaan model deret waktu yang didapatkan adalah:

$Y_{t}=5.54+0.65 Y_{t-1}+e_{t}+0.305 e_{t-1}$

$-0.118 e_{t-2}+0.187 e_{t-3}+0.007 e_{t-4}$

$+0.253 e_{t-5}-0.027 e_{t-6}-0.15 e_{t-7}+$

$0.061 e_{t-8}-0.012 e_{t-9}-0.055 e_{t-10}$

$+0.122 e_{t-11}-0.682 e_{t-12}$

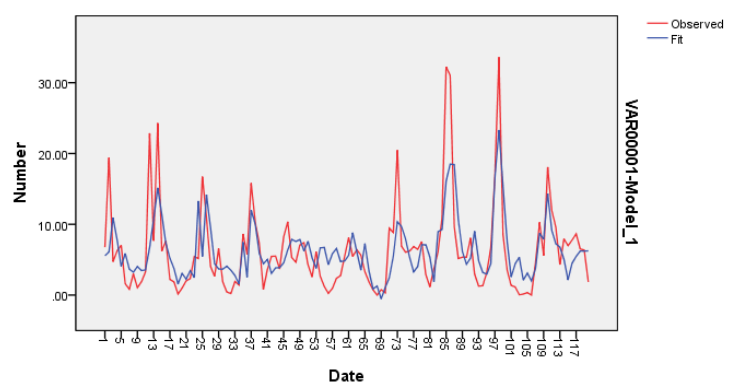

Gambar 3. Plot data observasi (garis merah) dengan hasil pemodelan ARIMA $(1,0,12)$ (garis biru)

Dari plot grafik di atas, tampak bahwa data hasil model ARIMA $(1,0,12)$ sebagian sesuai kecil sesuai dengan data observasi karena memang hanya 41,3\% kecocokan model dan observasi.

3.6 Prediksi Curah Hujan di Tahun 2017 dan Perbandingannya dengan Data Validasi (Hasil Observasi)

Untuk memprediksi curah hujan di tahun 2017, digunakan persamaan model deret waktu (1) yang sudah diperoleh. $\widehat{Y}_{t}$ menyatakan nilai taksiran estimasi curah hujan rata-rata di bulan $\mathrm{t}$ pada tahun 2017.

Tabel 2. Tabel prediksi curah hujan rata-rata per bulan di tahun 2017 dan data validasi 


\begin{tabular}{|c|c|c|c|}
\hline Bulan & $\widehat{\boldsymbol{Y}_{\boldsymbol{t}}}$ & Data Validasi & Galat relatif \\
\hline Januari 2017 & 8.56 & 9.94694 & 0.13943 \\
\hline Februari 2017 & 18.92 & 23.3 & 0.18798 \\
\hline Maret 2017 & 6.1 & 5.90909 & 0.032308 \\
\hline April 2017 & 7.82 & 6.64878 & 0.176156 \\
\hline Mei 2017 & 4.08 & 4.27273 & 0.04511 \\
\hline Juni 2017 & 5.88 & 7.59524 & 0.22583 \\
\hline Juli 2017 & 3.66 & 4.08158 & 0.10329 \\
\hline Agustus 2017 & 1.23 & 0.06279 & 18.58889 \\
\hline September 2017 & 4.04 & 5.86341 & 0.31098 \\
\hline Oktober 2017 & 3.46 & 3.95 & 0.12405 \\
\hline November 2017 & 7.56 & 7.53256 & 0.003643 \\
\hline Desember 2017 & 7.73 & 9.33469 & 0.17191 \\
\hline
\end{tabular}

Dari tabel diatas, dapat dilihat adanya perbedaan yang tidak terlalu signifikan antara hasil prediksi dan data validasi (hasil observasi) curah hujan rata-rata di tahun 2017. Perbedaan yang ada disebabkan oleh faktor galat, dimana variansi dari galat membesar seiring menjauhnya rentang waktu dari data deret waktu terakhir. Galat tersebut dapat dikarenakan fakta bahwa curah hujan rata-rata per bulan merupakan proses stokastik yang dipengaruhi oleh faktor eksternal, antara lain iklim yang berubah-ubah, suhu, tekanan, dan lain-lain.

\subsection{Pengaruh Curah Hujan Terhadap Banjir}

Dalam menganalisis faktor-faktor penyebab banjir maka perlu dilakukan analisis tambahan malalui analisis meteorologi dengan bantuan citra satelit cuaca, SST, dan streamline pada saat kejadian. Penyebab banjir dipengaruhi oleh kemampuan saluran drainase dan pengendali banjir untuk mengalirkan limpasan permukaan. Jika data yang dimiliki hanya berupa data curah hujan, maka diperlukan analisis curah hujan dengan periode ulang (T). Analisis frekuensi data curah hujan maksimum salah satunya dapat dilakukan dengan metode Gumbel. Pemilihan distribusi analisis Gumbel didasarkan hasil pengujian kecocokan (testing of goodness of fit) dengan uji Chi-kuadrat dan uji SmirnovKolmogorov. Metode analisis Gumbel berdasarkan atas karakteristik dari pemencaran dengan menggunakan suatu koreksi yang variabel. Angka koreksi ini merupakan suatu fungsi dari nomor urut relatif dalam serinya (m:N) dan sifat pemencarannya (Subarkah, 1980).
Persamaan yang digunakan untuk menghitung periode ulang adalah: (Nugroho, 2008)

$$
T=\frac{1}{m+c-1}
$$

dimana:

$\mathrm{T} \quad$ : $\quad$ periode ulang

$\mathrm{m} \quad$ : nomor urut data mulai dari

yang terbesar

c : koreksi Gumbel yang merupakan fungsi dari nomor urut relatif dalam serinya dan sifatnya.

Probabilitas $(\mathrm{P})$ yang ditimbulkan suatu harga sama dengan atau kurang dari $\mathrm{X}$ karena data curah hujan yang digunakan merupakan hargaharga maksimum dari banyak seri, hal ini ditentukan oleh persamaan:

$$
P=e^{-e^{-y}}
$$

dimana:

y : variabel tanpa dimensi, $\mathrm{y}=$ $a(X-X f)$, dengan $a=\frac{1,2825}{\sigma_{x}}$

$\mathrm{Xf}:$ modus, diperoleh dari $\mathrm{Xf}=\mathrm{x}-$ $0,45 \sigma_{x}$

$\sigma_{x} \quad: \quad$ penyimpangan standar terhadap harga rata-ratanya

$\mathrm{X}$ : $\quad$ harga rata-rata dari $\mathrm{X}$

Berdasarkan analisis frekuensi hujan dengan metode Gumbel maka dapat disusun suatu hubungan antara curah hujan harian maksimum dengan periode ulangan (Gambar 4).

Dengan demikian, stasiun hujan dengan $\mathrm{T}$ sebesar 150 tahun menunjukkan kemungkinan sebesar $0,4 \%$ terjadinya curah hujan yang sama atau lebih besar dari $250 \mathrm{~mm} /$ hari untuk setiap 
tahun. Demikian pula halnya dengan perode ulang 7 tahunan yang menunjukkan kemungkinan terjadinya curah hujan yang sama atau lebih besar dari $147 \mathrm{~mm} /$ hari untuk setiap tahunnya adalah sebesar $14,3 \%$. Curah hujan yang sedemikian besar menyebabkan banjir terjadi hampir merata di daerah Jakarta dan sekitarnya. Hampir seluruh sungai di Jakarta memiliki tinggi muka air yang melebihi tinggi muka air normal dan sungai yang ada tidak mampu menampung dan mengalirkan air tersebut ke laut sehingga akan terjadi luapan di sepanjang sungai.

\section{KESIMPULAN}

Curah hujan rata-rata per bulan di Jakarta dapat dmodelkan dengan time series gabungan antara AR (Auto Regressive) dam MA (Moving Average). Model yang paling sesuai adalah model ARIMA $(1,0,12)$ dengan nilai Stationary $R$-squared sebesar 498 dan nilai MAPE (Mean Absolute Percentage Error) sebesar 220.058. Dengan model tersebut, dibentuk persamaan model untuk estimasi berupa persamaan (1). Estimasi yang didapatkan dari persamaan untuk curah hujan rata-rata per bulan di tahun 2017 dan perbandingannya dengan data validasi dilampirkan di Tabel 2. Dalam menganalisis penyebab banjir perlu dilakukan analisis tambahan yang melibatkan banyak faktor. Oleh karena data yang dimiliki hanya berupa data curah hujan maka dilakukan analisis curah hujan dengan periode ulang $(\mathrm{T})$ melalui metode Gumbel. Berdasarkan analisis frekuensi hujan dengan metode Gumbel diperoleh suatu hubungan antara curah hujan harian maksimum dengan periode ulangan. Melalui hubungan tersebut, hubungan curah hujan terhadap potensi banjir diestimasi secara kualitatif untuk membantu mengantisipasi bencana banjir di Jakarta.

\section{DAFTAR PUSTAKA}

Amoateng, P., Finlayson, C. M., Howard, J., dan Wilson, B. 2018. A multi-faceted analysis of annual flood incidences in Kumasi, Ghana. International Journal of Disaster Risk Reduction 27, 105-117.

Arumugam, P., dan Karthik, S. M. 2018. Stochastic Modelling in Yearly Rainfall at Tirunelveli District, Tamil Nadu, India.
Materials Todays: Proceeding 5, 18521858.

BMKG. 2018, Data Curah Hujan Harian Satuan Milimeter (mm) Periode 2007-2017 DKI Jakarta, Jakarta.

Chang, J. M., Chen, H., Jou, B. J. D., Tsou, N. C., dan Lin, G. W. 2017. Characteristics of rainfall intensity, duration, and kinetic energy for landslide triggering in Taiwan. Engineering Geology 231, 81-87.

Costa, V. dan Fernandes, W. 2017. Bayesian estimation of extreme flood quantiles using a rainfall-runoff model and a stochastic daily rainfall generator. Journal of Hydrology. 554, 137-154.

Douka, M. dan Karacostas, T. 2017. Statistical analyses of extreme rainfall events in Thessaloniki, Greece. Atmospheric Research. 2017. 08. 025.

Duangdai, E. dan Likasiri, C. 2015. Mathematical model analyses on the effects of global temperature and forest cover on seasonal rainfalls: A Northern Thailand case study. Journal of Hydrology. 524, 270-278.

Estiningtyas, W., Boer, R., dan Buono, A. 2009. Analisis Hubungan Curah Hujam dengan Kejadian Banjir dan Kekeringan pada Wilayah dengan Sistim Usahatani Berbasis Padi di Propinsi Jawa Barat. J. Agromet 23, 11-19.

Firman, T., Surbakti, I. M., Idroes, I. C., dan Simarmata, H. A. 2011. Potential ClimateChange Related Vulnerabilities In Jakarta: Challenges And Current Status. Habitat International. 35. 372-378.

Jimoh, O. D., dan Webster, P. 1996. The optimum order of a Markov chain model for daily rainfall in Nigeria. Journal of Hydrology 185, 45-69.

Litman, T. 1995. Land use impact costs of transportation. World transport policy practice. Vol. 1. World transport policy and practice, 9-16.

Nugroho, S. P. 2008. Analisis Curah Hujan Penyebab Banjir Besar di Jakarta pada Awal Februari 2007. JAI. Vol. 4. No.1.

Saputro, D. R. S., Wigena, A. H. dan Djuraidah, A., 2011. Model Vektor Autoregressive untuk Peramalan Curah Hujan di 
Indramayu. Forum Statistika dan Komputasi. Vol. 16 no. 2, 7-11.

Satterthwaite, D., 2008. Climate change and urbanization: Effects and implications for urban governance. Population Division e Department of Economic and Social Affairs. United Nations Secretariat. 21-23.

Siswanto, V. S. G., Oldenborgh, G., Hurk, B., Aldrian, E., Swarinoto, Y., Sulistya, W., dan Sakya, A. E. 2017. A Very Unusual Precipitation Event Associated With The 2015 Floods In Jakarta: an analysis of the meteorological factors. Weather and Climate Extremes 16, 23-28.

So, B. J., Kwon, H. H., Kim, D., dan Lee, S. O. 2015. Modeling of daily rainfall sequence and extremes based on a semiparametric Pareto tail approach at multiple locations. Journal of Hydrology. 529. 1442-1450.

Subarkah, I. 1980. Hidrologi Untuk Perencanaan Bangunan Air. Idea Dharma. Bandung.

Yusuf, A. A. dan Fransisco, H. 2009. Climate change vulnerability mapping for Southeast Asia. Singapore. Economy and Environment Program for Southeast Asia.

Zhang, J., Li, Y., Huang, G., Chen, X., dan Bao, A. 2016. Assessment Of Parameter Uncertainty In Hydrological Model Using A Markov-Chain-Monte-Carlo-Based Multilevel-Factorial-Analysis Method. Journal of Hydrology. 538. 471-48 
